\title{
Protective Effect of the Grape Seed Proanthocyanidin Extract in a Rat Model of Contrast-Induced Nephropathy
}

\author{
Gulsum Ozkan $^{a}$ Sukru Ulusoy ${ }^{\mathrm{a}}$ Asım Orem $^{\mathrm{b}}$ Safak Ersoz $^{\mathrm{c}}$ Mehmet Alkanat $^{\mathrm{d}}$ \\ Fulya Balaban Yucesan $^{\mathrm{b}}$ Kubra Kaynar $^{\mathrm{a}}$ Sait $\mathrm{Al}^{\mathrm{e}}$

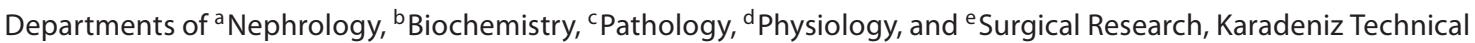 \\ University, School of Medicine, Trabzon, Turkey
}

\section{Key Words}

Contrast-mediated nephropathy · Grape seed proanthocyanidin - Grape seed proanthocyanidin extract • Malondialdehyde $\cdot$ Oxidative system $\cdot$ Apoptosis

\begin{abstract}
Aim: Contrast-induced nephropathy (CIN) is a common cause of hospital-acquired acute renal failure. Although it is so common, there has been no approved therapy yet. We aimed to investigate the effect of grape seed proanthocyanidin extract (GSPE) on preventing CIN. Materials and Methods: 24 rats were divided into four groups as control group, GSPE group, contrast medium (CM) group, and $\mathrm{CM}+\mathrm{GSPE}$ group. The experiment was discontinued on the ninth day. Blood samples were obtained for the measurement of renal function parameters. Renal tissues of the rats were removed for the analysis of oxidative system parameters. In addition to renal histopathology, transferase-mediated deoxyuridine triphosphate nick end labeling (TUNEL) was performed to determine apoptosis. Results: There was a significant increase in BUN, creatinine, malondialdehyde (MDA) levels, apoptotic index (Al) and histopathological alteration in the CM group as compared to the control group. Further-
\end{abstract}

more, BUN, creatinine, MDA, total oxidant system and oxidative stress index levels, Al as well as renal histopathological alteration were significantly decreased in the CM+GSPE group. Conclusion: For the first time in the literature, we showed that GSPE provided biochemical and histopathological improvement in CIN. Our findings revealed that this improvement was associated with the decrease in oxidative damage and apoptosis.

Copyright $\odot 2012$ S. Karger AG, Base

\section{Introduction}

As the use of imaging methods increases, so does the frequency of contrast-induced nephropathy (CIN). CIN is defined as an otherwise unexplained impairment in renal functions $48-72 \mathrm{~h}$ after receiving iodine contrast agent. The European Society of Urogenital Radiology defines impaired renal functions as a $25 \%$ or $0.5 \mathrm{mg} / \mathrm{dl}$ increase in basal creatinine levels [1]. The exact incidence of CIN is unknown, due to the fact that contrast imaging examinations are generally performed in outpatient settings or that hospitalized patients are discharged $24 \mathrm{~h}$ after contrast imaging without biochemical analysis being

\section{KARGER \\ Fax +4161306 1234 \\ E-Mail karger@karger.ch}

www.karger.com (c) 2012 S. Karger AG, Basel

$1420-4096 / 12 / 0356-0445 \$ 38.00 / 0$

Accessible online at:

www.karger.com/kbr
Dr. Gülsüm Özkan

Karadeniz Teknik Üniversitesi, Tip Fakültesi

Nefroloji Bilim Dalı

TR-61080 Trabzon (Turkey)

Tel. +90 462377 5711, E-Mail gulsumozkan78@ hotmail.com 
performed. Although the pathogenesis of CIN has not been completely elucidated, direct tubular toxicity of contrast medium (CM), a decrease in renal blood flow, oxidative damage and apoptosis are the most commonly involved mechanisms in the pathogenesis $[2,3]$.

Proanthocyanidins are polyphenolic antioxidants commonly found in vegetables, fruits and various flowers [4]. In addition to lipid peroxidation, thrombocyte aggregation and capillary permeability-reducing effects, they also have antibacterial, antiviral and anti-inflammatory characteristics. They exhibit these effects by modulating various enzymes, including cyclooxygenase and lipoxygenase [4, 5]. Grape seed proanthocyanidin extract (GSPE) is derived from grape seeds. In vivo and in vitro studies have shown that GSPE has an antioxidant effect superior to those of vitamins $\mathrm{C}, \mathrm{E}$ and $\beta$-carotene [6]. Moreover, cell culture studies have demonstrated its anticarcinogenic effect, and various animal studies have shown its antiapoptotic effect $[4,5]$.

In this study, we aimed to show the effect of GSPE on CIN, which has not been studied experimentally before. In order to demonstrate this effect, we investigated oxidative changes, which play a role in the pathogenesis of CIN, by evaluating blood urea nitrogen (BUN) and creatinine levels, total oxidant system (TOS), total antioxidant system (TAS), oxidative stress index (OSI) and malondialdehyde (MDA) levels. Renal histopathological examinations were performed on renal tissue to show renal damage, and transferase-mediated deoxyuridine triphosphate nick end labeling (TUNEL) was used to reveal apoptosis.

\section{Materials and Methods}

A total of 24 adult, 8- to 10-week-old female Sprague-Dawley rats weighing 200-250 g were used. The rats were kept in cages in a $12 \mathrm{~h}$ light and $12 \mathrm{~h}$ dark cycle at $22 \pm 2{ }^{\circ} \mathrm{C}$ and were provided with food and water ad libitum. The study was approved by Karadeniz Technical University School of Medicine Animal Ethics Committee. Experimental animals were cared for and used in accordance with the National Institute of Health Guide.

\section{Chemicals}

GSPE $(0.5 \mathrm{ml}$ extract solution with $66.7 \mathrm{mg} / \mathrm{g}$ total phenolic substance and oligomeric proanthocyanidin ratio of $95 \%$ containing 100 mg GSPE; Kale Natural Herbal Products Food, Cosmetic \& Agricultural Products Ltd, Edremit/Balikesir, Turkey), diatrizoate (Urografin ${ }^{\circledR} 50-\mathrm{ml} \mathrm{flk} / 370 \mathrm{mg} \mathrm{I} / \mathrm{ml}$; Schering), ketamine (Ketalar ${ }^{\circledR} 500 \mathrm{mg}$ injectable flk; Pfizer, Istanbul, Turkey), and xylazine (Rompun ${ }^{\circledR} 50$-ml flk; Bayer, Istanbul, Turkey).

\section{Study Protocol}

After 5 days of acclimatization, the 24 rats were randomly divided into four groups of 6 animals each: control, GSPE, CM and
$\mathrm{CM}+\mathrm{GSPE}$ groups. The rats were weighed on the first day of the study. The rats in the groups were kept in separate cages and had free access to standard rat chow and water (except for the days of dehydration).

The control and CM groups were given $1 \mathrm{~cm}^{3}$ of $0.9 \%$ normal saline via gavage for 5 days, whereas the GSPE and CM+GSPE groups were given $100 \mathrm{mg} / \mathrm{kg}\left(1 \mathrm{~cm}^{3}\right)$ of GSPE via gavage for 5 days $\left(0.5 \mathrm{~cm}^{3}\right.$ of grape seed extract including $100 \mathrm{mg}$ of GSPE, the final $1 \mathrm{~cm}^{3}$ of solution being obtained by adding $0.9 \%$ normal saline). All rats were allowed chow and water ad libitum during this period. On the sixth day, the rats in the CM and CM+GSPE groups were left without water for $24 \mathrm{~h}$. On the seventh day, $7 \mathrm{ml} /$ $\mathrm{kg}$ of diatrizoate (approx. $1.3 \mathrm{~cm}^{3}$ ) was administered to the $\mathrm{CM}$ and CM+GSPE groups [7], while approximately $1.3 \mathrm{~cm}^{3}$ of $0.9 \%$ saline was administered to the control and GSPE groups by slow infusion through the tail vein over $5 \mathrm{~min}$. The rats were then fed via gavage for 2 more days. Rats in all groups were allowed chow and water ad libitum over these 2 days. On the ninth day, $48 \mathrm{~h}$ after CM administration, the rats were anesthetized with $90 \mathrm{mg} /$ $\mathrm{kg}$ of ketamine and $10 \mathrm{mg} / \mathrm{kg}$ of xylazine, and a midline incision was performed. Renal tissues were quickly removed. The rats were exsanguinated, and the experiment was terminated after obtaining $2 \mathrm{~cm}^{3}$ intracardiac blood samples for biochemical analysis.

\section{Biochemical Analysis}

BUN and creatinine measurements were performed using a Roche autoanalyzer (Modular System, GmbH, Mannheim, Germany). Following decapsulation of the kidneys, longitudinal dissection was performed. Half the tissue samples were stored at $-80^{\circ} \mathrm{C}$ until MDA, TAS, TOS and OSI measurement. At time of analysis, rat kidney tissues were weighed and homogenized in an ice-cold $1.15 \% \mathrm{KCl}$ solution containing $0.50 \mathrm{ml} /$ Triton X-100 using an UltraTurrax T18 basic homogenizer (IKA Inc., Wilmington, N.C., USA). The homogenate was centrifuged at 4,000 rpm for $5 \mathrm{~min}$ at $4^{\circ} \mathrm{C}$, and supernatant was used for the determination of MDA, TAS and TOS levels.

Tissue MDA levels were assigned according to the method described by Uchiyama and Mihara [8]. Tetramethoxypropane was used as a standard, and tissue MDA levels are given as nmol/g wet tissue.

Tissue TAS, TOS and OSI levels were assayed as described previously [9] using commercial assay kits (Rel Assay Diagnostics, Gaziantep, Turkey; product Nos. RL0017 and RL0024, respectively). Tissue TAS levels are given as $\mu \mathrm{mol}$ Trolox equivalents (EQ)/g wet tissue and TOS levels as $\mu \mathrm{mol} \mathrm{H}_{2} \mathrm{O}_{2} \mathrm{EQ} / \mathrm{g}$ wet tissue. OSI values were calculated using the formula [(TOS, $\mu \mathrm{mol} \mathrm{H}_{2} \mathrm{O}_{2} \mathrm{EQ} / \mathrm{g}$ wet tissue)/(TAS, $\mu$ mol Trolox EQ/g wet tissue) $] \times 100$.

\section{Histopathological Evaluation}

The other halves of the decapsulated kidneys were used for pathological examination. Specimens were fixed in 10\% formalin solution. For light microscopy, they were dehydrated using 70 and $100 \%$ alcohol solutions, processed in an Autotechnicon and embedded in paraffin. Sections $4 \mu \mathrm{m}$ thick were cut using a microtome and stained with hematoxylin and eosin (HE). Stained specimens were assessed by a pathologist in a blinded fashion using an Olympus BX50 (Japan) light microscope. The specimens were scored according to the presence of tubular necrosis and atrophy, cytoplasmic vacuoles, glomerular injury, vascular congestion and 


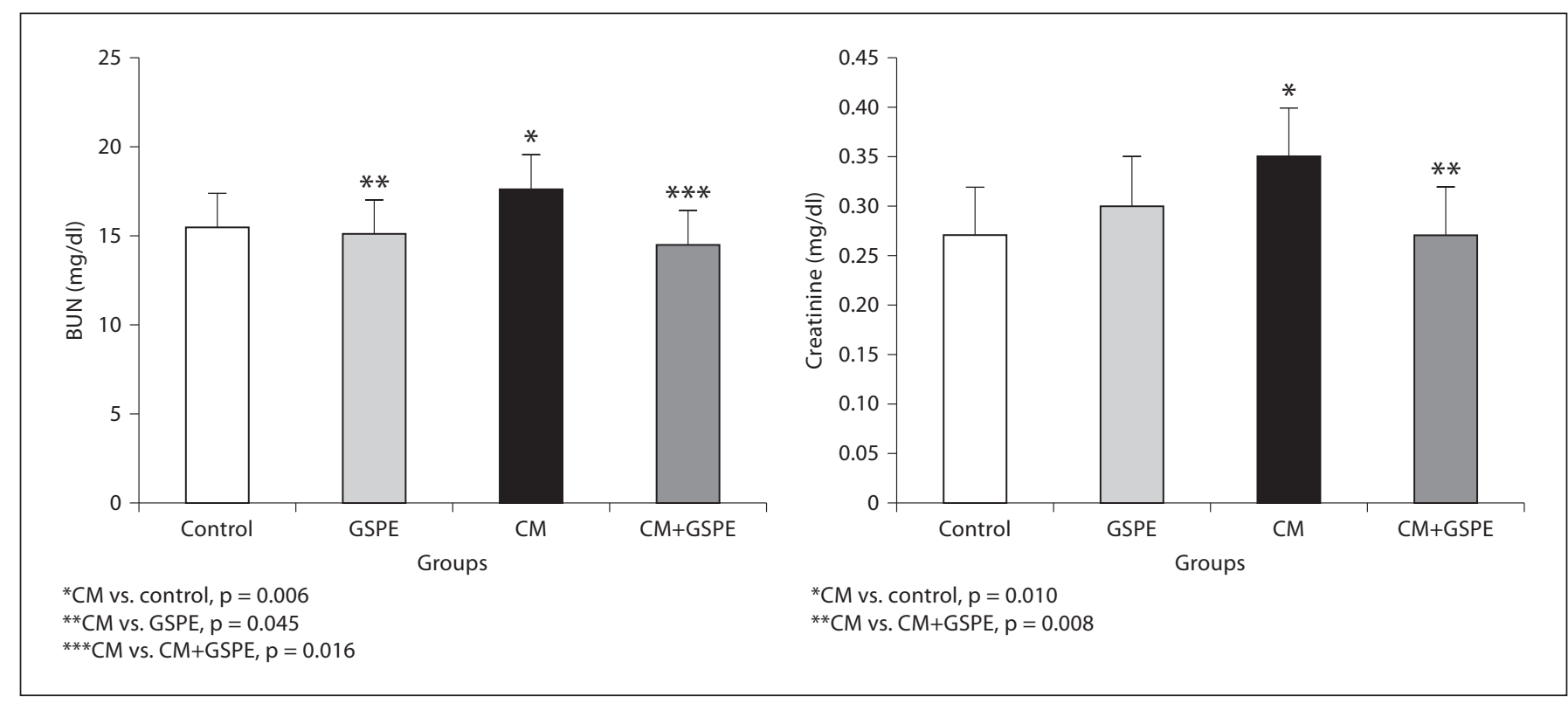

Fig. 1. Comparison of the effect of GSPE on serum BUN and creatinine levels. BUN and creatinine levels significantly increased in the CM group compared with the control group, and significantly decreased in the $\mathrm{CM}+\mathrm{GSPE}$ group compared with the CM group. Values are expressed as mean $\pm \mathrm{SD}$.

thrombosis and interstitial infiltration. The following scoring system was used for the histopathological evaluation of tissues under light microscopy: $0=$ normal kidney, $1=$ minimal injury $(0-5 \%), 2=$ moderate injury $(5-25 \%), 3$ = intermediate injury $(25-$ $75 \%)$, and $4=$ severe injury (75-100\%) [7].

\section{TUNEL Method}

To label apoptotic cells, tissue samples were fixed in formalin and embedded in paraffin; 4 - $\mu \mathrm{m}$-thick serial sections were then prepared from the tissue samples. A standard terminal deoxynucleotidyl transferase (TdT) deoxyuridine TUNEL assay technique was used to detect the fragmented DNA associated with apoptosis. TUNEL staining of sections was performed using an In Situ Cell Death Detection Kit AP (Roche, Mannheim, Germany) in accordance with the manufacturer's instructions, and the sections were then examined under light microscopy. After standard deparaffinization, the sections were hydrated and immersed in a solution of 3\% hydrogen peroxidase for endogenous peroxidase blocking. The sections were incubated in a humidified chamber with the TUNEL reaction mixture. Color was then developed with diaminobenzidine tetrahydrochloride (Sigma, St. Louis, Mo., USA), and the sections were counterstained with Harris hematoxylin. For the negative controls, the sections were processed in a TdT enzyme-free solution. The TUNEL staining cells appeared brown, and the nuclei of the other cells appeared blue. The stained sections were examined under a light microscope at $\times 400$ magnification. One hundred cells were counted in five microscopic fields per tissue slide. The percentage of TUNEL-positive apoptotic cells was measured, representing the apoptotic index (AI).

\section{Statistical Analysis}

Statistical analysis was performed using SPSS 13.0. The results were expressed as mean \pm SD. Groups were examined for normal distribution. Kruskal-Wallis variance analysis and Mann-Whitney $\mathrm{U}$ test were used for the comparison of BUN, creatinine, MDA, TOS, TAS, OSI, renal pathological findings and AI. p values $<0.05$ were considered statistically significant.

\section{Results}

\section{Effect of GSPE on Biochemical Parameters}

BUN and creatinine levels were significantly elevated in the CM group compared to the control group ( $\mathrm{p}=$ 0.006 and $\mathrm{p}=0.010$, respectively) (fig. 1). However, this elevation decreased significantly in the CM+GSPE group ( $\mathrm{p}=0.016$ for BUN and $\mathrm{p}=0.004$ for creatinine). On the other hand, no significant difference was observed between the CM+GSPE and control groups in terms of BUN and creatinine levels $(\mathrm{p}=0.873$ and $\mathrm{p}=0.686$, respectively).

\section{Effect of GSPE on Oxidative Parameters}

As shown in figure 2, there was no significant difference between the GSPE group and control group in terms of TAS, TOS, OSI and MDA levels. The MDA level significantly increased in the CM group compared to the 


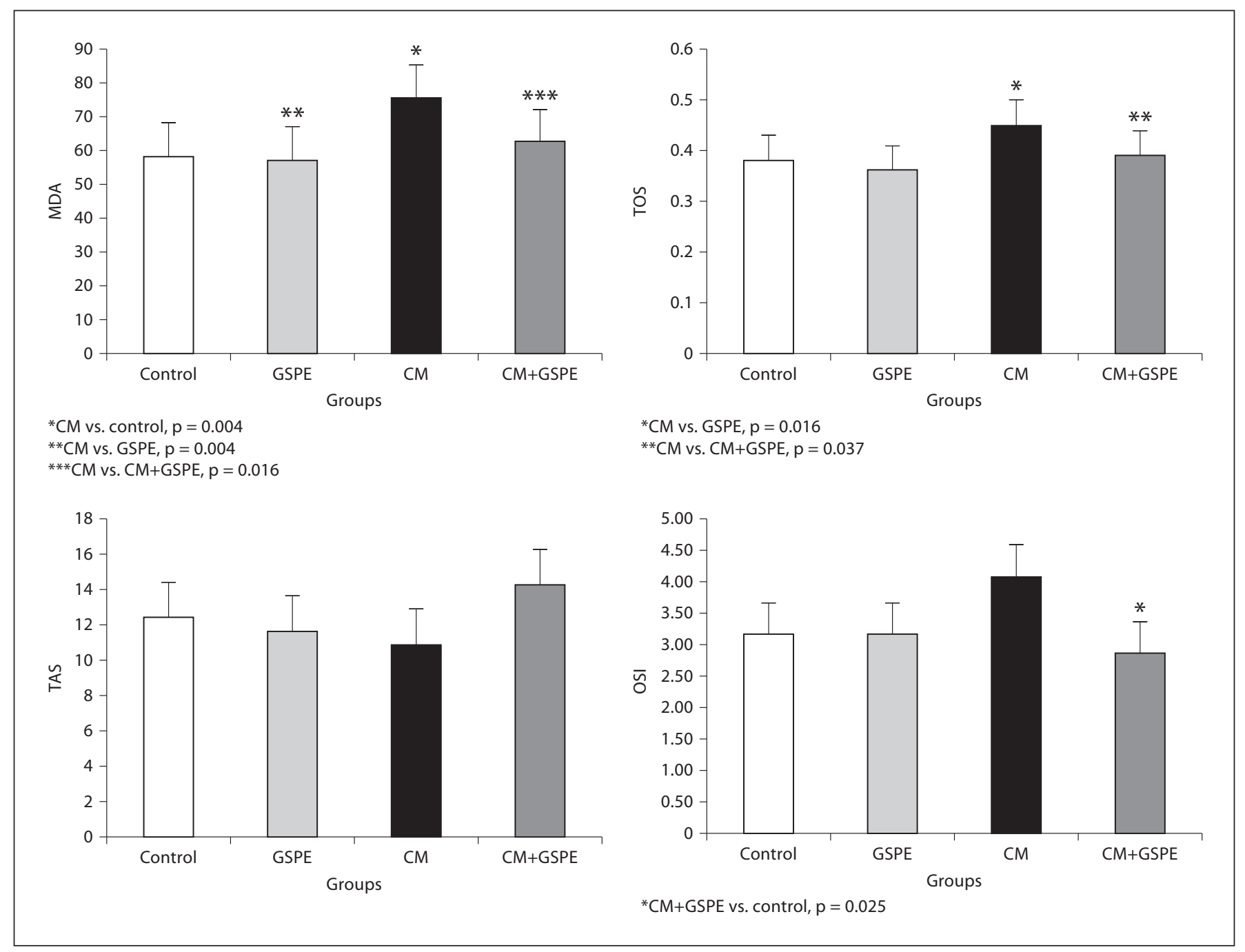

Fig. 2. Comparison of the effect of GSPE on TOS, TAS, OSI and MDA levels. MDA levels significantly increased in the CM group compared with the control group. MDA and TOS levels significantly decreased in the CM+GSPE groups. TOS: $\mu \mathrm{mol} \mathrm{H} \mathrm{H}_{2} \mathrm{O}_{2}$ EQ/g wet tissue; TAS: $\mu \mathrm{mol}$ Trolox EQ/g wet tissue; OSI: [(TOS, $\mu \mathrm{mol} \mathrm{H}_{2} \mathrm{O}_{2}$ EQ/g wet tissue)/(TAS, $\mu \mathrm{mol}$ Trolox EQ/g wet tissue) $] \times 100$. MDA: $n$ mol/g wet tissue.

control group ( $p=0.004)$, however there was no significant difference between these two groups in terms of TAS and OSI indexes ( $\mathrm{p}=0.199$ and $\mathrm{p}=0.109$, respectively). Although TOS levels increased in the CM group compared to the control group, the difference was not statistically significant $(\mathrm{p}=0.054)$. Moreover, when the CM group was compared with the GSPE group, MDA and TOS levels were significantly higher in the CM group ( $\mathrm{p}=0.004$ and $\mathrm{p}=0.016$, respectively). However, there was no significant difference between these groups in terms of TAS and OSI indexes. When the CM+GSPE group was compared with the CM group, MDA, TOS and OSI levels were significantly lower in the CM+GSPE group ( $\mathrm{p}=$ $0.041, p=0.037$ and $p=0.025$, respectively). Although the TAS level in the CM+GSPE group was higher compared to the CM group, the difference was not statistically significant (0.054). The MDA level of the CM+GSPE group decreased, but no significant difference was observed compared with the control group $(\mathrm{p}=0.423)$.

\section{Effect of GSPE on Renal Histopathology and} Apoptotic Index

No pathological findings were noted in renal samples from the GSPE and control groups. Extensive vascular 
Fig. 3. a Control. b GSPE. No pathological findings were noted in renal samples from the GSPE and control groups. Kidney with normal appearance $(\mathrm{HE}, \times 200)$. c CM. Extensive vascular congestion, tubular vacuoles, interstitial infiltration, perivascular edema, hyaline cast and tubular desquamation noted in renal proximal tubular cells. Glomeruli are intact $(\mathrm{HE}, \times 200)$. Arrow 1: vascular congestion; arrow 2: interstitial infiltration; arrow 3: perivascular edema; arrow 4: tubular vacuoles and desquamation. d CM. Arrow 5: hyaline cast. e $\mathrm{CM}+\mathrm{GSPE}$. Mild perivascular edema, vascular congestion and tubular vacuoles are noted in renal proximal tubular epithelial cells $(\mathrm{HE}, \times 200)$. Arrow 1: perivascular edema; arrow 2: vascular congestion; arrow 3: tubular vacuoles.
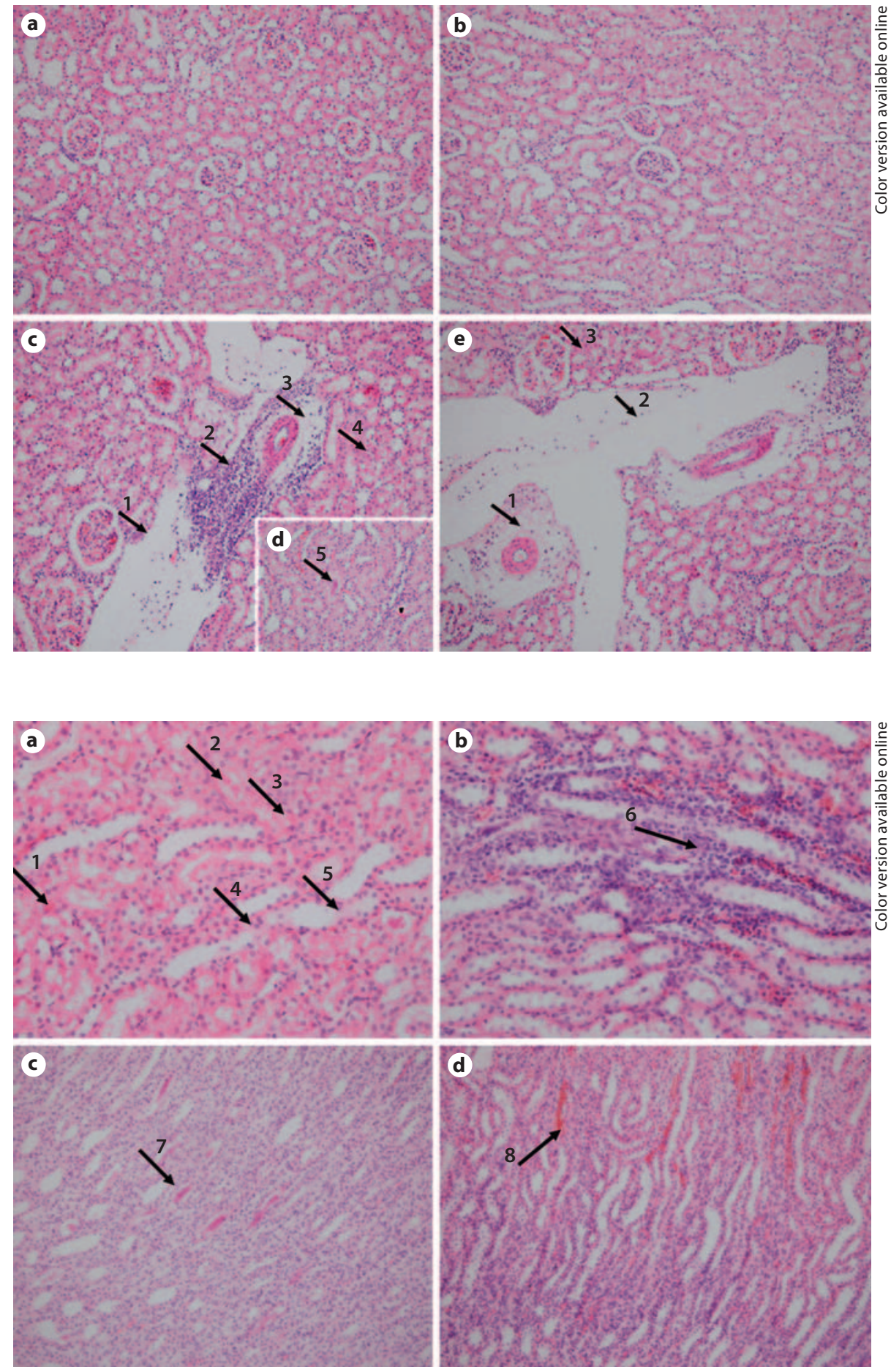

Fig. 4. CM group. a Arrows 1-3: extensive desquamation and focal necrosis noted in renal tubular cells (outer medulla); arrows 4, 5: impaired integrity and desquamation noted in in renal tubular cells (outer medulla) (HE, $\times 400)$. b Arrow 6: interstitial infiltration $(\mathrm{HE}, \times 400)$. c Arrow 7: hyaline cast $(\mathrm{HE}, \times 200)$. d Arrow 8: medullary congestion $(\mathrm{HE}, \times 200)$.

congestion, tubular vacuoles, interstitial infiltration, perivascular edema, hyaline cast, focal necrosis and tubular desquamation were observed in the CM group renal tubular cells (fig. 3, 4). Mild perivascular edema, vascular congestion and tubular vacuoles were noted in renal tubular epithelial cells of the CM+GSPE group (fig. 3). These histopathological findings were then scored. Of the rats in the CM group, 3 had grade 2 renal injury, 2 had grade 1 injury, and 1 rat had grade 0 injury; in the CM+GSPE group, however, 2 rats had grade 1 renal in- 


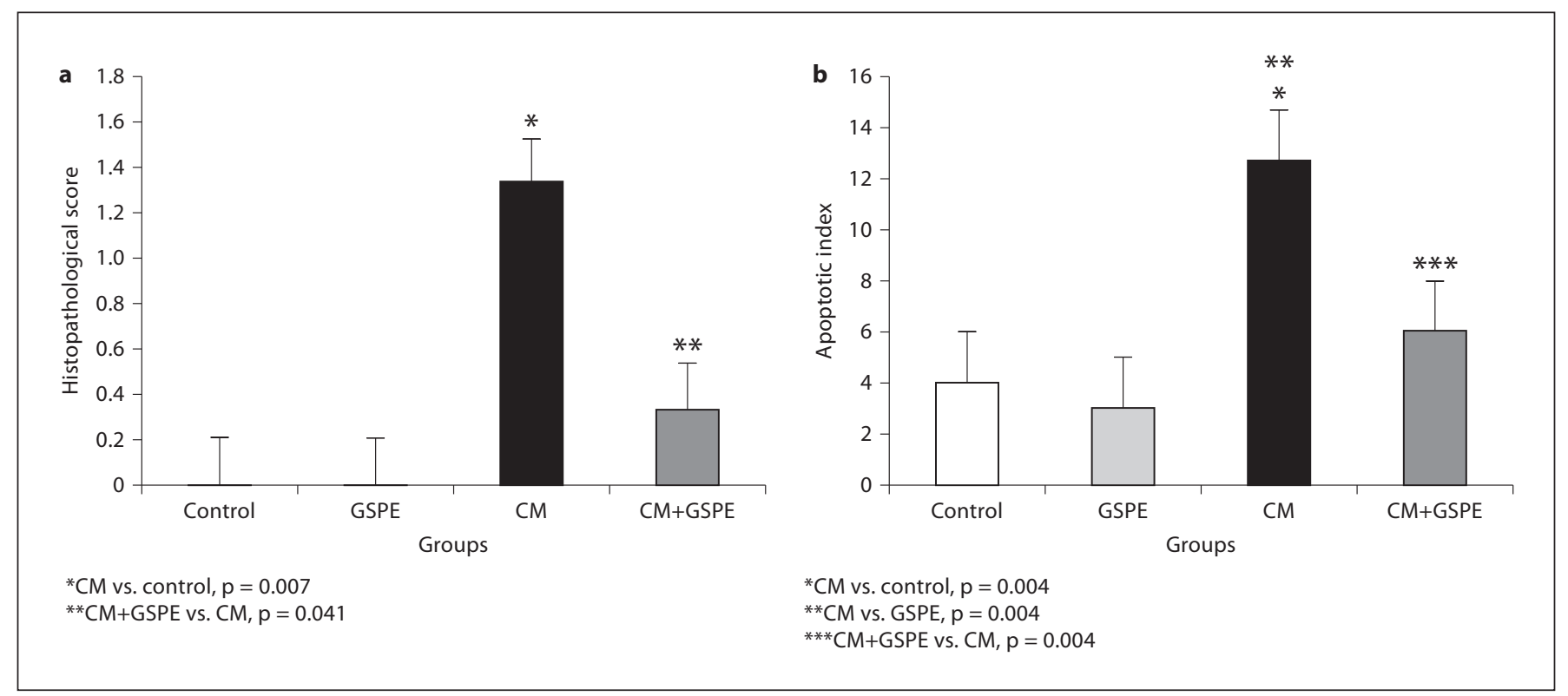

Fig. 5. Comparison of renal histopathological grade (a) and AI (b). The AI in tubular cells and histopathological score significantly increased in the CM group compared with the control group. The AI in tubular cells and histopathological score significantly decreased in the CM+GSPE group compared with the CM group. Values are expressed as mean $\pm \mathrm{SD}$.

jury and 4 had grade 0 injury. No renal histopathological alteration was present in the control or GSPE groups. When the CM group was compared with the control group, the renal histopathological alteration was significant ( $p=0.007$; fig. 5). Renal injury was significantly improved in the CM+GSPE group compared to the CM group ( $p=0.041)$. No significant difference was determined between $\mathrm{CM}+\mathrm{GSPE}$ group and the control group in terms of histopathological alteration $(\mathrm{p}=0.138$; fig. 5$)$. AI was the highest in the CM group (fig. 6). The $\mathrm{p}$ value obtained from comparison between the CM and control groups was 0.004 . AI decreased in the $\mathrm{CM}+\mathrm{GSPE}$ group compared with the CM group ( $\mathrm{p}=0.004)$ (fig. 5).

\section{Discussion}

CIN has become a common iatrogenic condition due to the increased use of imaging methods. Nonetheless, despite its high prevalence, there is still no effective and widely accepted agent used in its treatment. Studies on preventive measures have therefore increased in importance.

Although the underlying cellular mechanism of CIN is not well understood, a direct toxic effect of $\mathrm{CM}$ on the tubular cells and/or a decrease in renal blood flow are the most frequently encountered mechanisms [2]. Following $\mathrm{CM}$ administration, rapid and short-term vasodilatation occurs first, followed by prolonged vasoconstriction [10]. Therefore, various blood flow-increasing agents were clinically tested to prevent CIN; however, most of these have been reported to be ineffective [2]. In the experimental and/or clinical studies, caffeic acid phenyl ester (CAPE), $\mathrm{N}$-acetylcysteine (NAC) and ascorbic acid have been reported to have positive effects in preventing CIN [7, 11-14]. For this purpose, oxidative stress, rather than decrease in renal blood flow, is considered to play an important role in CIN development [2]. We measured the TOS, TAS and MDA levels in the CM group for the evaluation of oxidative stress status. A significant elevation was determined in MDA levels. We measured TOS and TAS levels to determine whether this elevation resulted from the activation of the oxidative system or a decline in the antioxidant system and observed an elevation in TOS levels, although not a significant one. Another mechanism held responsible in the pathogenesis of CIN is apoptosis. Several studies have shown that apoptosis increases in CIN through the intrinsic mitochondrial apoptotic pathway $[15,16]$. There was a particular increase in AI in the distal tubules in our study. We therefore concluded 
Fig. 6. Effect of GSPE on AI (outer medulla): a control, b GSPE, c CM, and d CM+GSPE. Apoptosis in tubular cells (especially distal tubular cells) significantly increased in the CM group and apoptosis in tubular cells significantly decreased in the CM+GSPE group (TUNEL × 200). Arrow: brown nuclei of apoptotic cells. Color in the color version only.
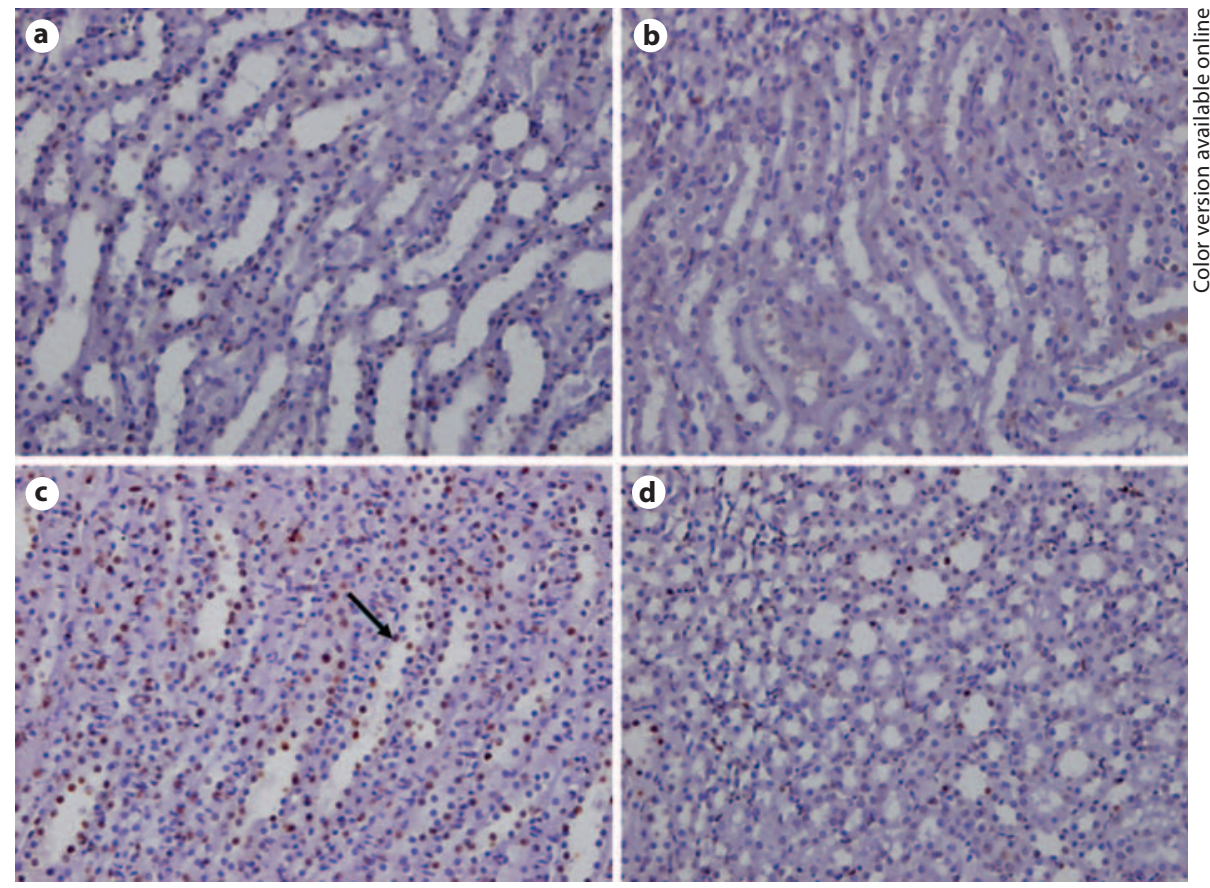

that an increase in the oxidative system and apoptosis were the cause of elevation in BUN and creatinine levels and of renal histopathological alteration.

No medication of proven efficacy in the treatment of CIN is currently available. In the light of its prevalence, studies regarding the prevention of CIN have therefore continued. Accepted preventive measures include identification of patients at high risk for CIN, discontinuation of potentially nephrotoxic medications $24 \mathrm{~h}$ before CM administration, adequate hydration with $0.9 \%$ saline or $1.4 \% \mathrm{Na} \mathrm{HCO}_{3}$, and reducing the osmolarity and volume of CM. As studies on the preventive effects of prophylactic hemodialysis, calcium channel blocker, dopamine, atrial natriuretic peptide, fenoldopam, prostaglandin $\mathrm{E}_{1}$, endothelin receptor antagonists, and ascorbic acid have produced contradictory results, these are not considered as preventive treatment modalities in $\operatorname{CIN}[2,13,14,17-$ 19]. Despite the contradictory results regarding the use of NAC in the prophylaxis of CIN, a previous review including a meta-analysis of eight studies reported that using NAC at a dose of $2 \times 600 \mathrm{mg} 1$ day before, on the day of, and 1 day after $\mathrm{CM}$ administration led to a decrease in the rate of CIN [20]. Moreover, one recent study reported that $2 \times 1,200 \mathrm{mg}$ of NAC is more effective than $2 \times 600$ $\mathrm{mg}$ [21]. However, 2,308 patients undergoing an intravascular angiographic procedure and with at least one risk factor for CMN (age $>70$ years, renal failure, diabetes mellitus, heart failure or hypotension) were included in the 2011 Acetylcysteine for Contrast-Induced Nephropathy Trial (ACT). That study compared acetylcysteine and placebo and determined no difference between the two groups in terms of preventing CIN [22]. Applying intravenous hydration, one of the accepted prophylactic modalities in CIN, can be troublesome in patients who require volume restriction because of diseases such as heart failure and cirrhosis. We therefore evaluated the efficacy of GSPE in preventing CIN, the antioxidant effect of which has been proven in experimental studies, but its efficacy in preventing CIN has not been investigated to date.

GSPE is a combination of biologically active polyphenolic flavonoids including oligomeric proanthocyanidin [4]. Vasodilator, anticarcinogenic, antiallergic, anti-inflammatory, antibacterial, cardioprotective, immunomodulator, and antiviral characteristics of GSPE have been shown in various experimental studies in addition to its reactive oxygen species scavenging and antioxidant features $[4,5]$. Its organ-specific protective effect has been shown in acetaminophen-induced hepatotoxicity, amiodarone-induced pulmonary toxicity, doxorubicin-induced cardiotoxicity [23], cisplatin-induced hepatotoxicity, cardiotoxicity, and renal toxicity [24]. The effect of GSPE in preventing renal damage has not been studied extensively, nor has its preventive effect on CMN ever 
been evaluated. In the literature, studies conducted on the effect of GSPE in preventing renal injury are limited to its effect on preventing cisplatin-induced nephrotoxicity, gentamycin-induced nephrotoxicity, and ischemiareperfusion renal injury. In the study evaluating the effects of GSPE on preventing cisplatin-induced nephrotoxicity, it was reported that GSPE use decreased the cisplatin-induced nephrotoxicity by increasing antioxidant enzymes [25]. The protective and oxidative stressreducing effects of GSPE were also demonstrated in the study investigating the protective effect of GSPE on renal ischemia-reperfusion injury [26]. In the study evaluating the preventive effect of GSPE on gentamycin-induced nephrotoxicity, biochemical and histopathological improvement was reported, however the effect of GSPE on the oxidative system was not evaluated [27]. No studies have evaluated the apoptotic effect of GSPE in renal tissue, though there are studies analyzing its apoptotic effect in preventing liver and heart injury $[28,29]$. Efrati et al. [30] evaluated the effects of NAC, theophylline and bicarbonate on preventing CIN and reported that the oxidative system was activated, however these medications caused no change in this system. A study evaluating the protective effect of CAPE and NAC in CIN has shown that antioxidant molecules decrease the MDA level and increase the catalase level [7].

For the first time in the literature, we observed the protective effect of GSPE in CIN development by means of administering $100 \mathrm{mg} / \mathrm{kg}$ GSPE via gavage 7 days before and 2 days after $7 \mathrm{ml} / \mathrm{kg}$ intravenous administration of diatrizoate. In the CM+GSPE group, the change in BUN and creatinine levels and renal histopathological findings regressed to such a point similar to that in the control group. According to the pathogenesis of the damage, no change was observed in TOS, TAS and MDA levels in the GSPE group. On the other hand, the MDA level was significantly increased in the CM group, whereas the increase in TOS level was not statistically significant. TOS and MDA levels were significantly higher in the CM group than those in the GSPE group. While MDA, TOS and OSI levels were significantly lower in the CM+GSPE group compared to the CM group, the TAS level was increased, but not statistically significantly. In addition, while there was a rise in $\mathrm{AI}$ in the $\mathrm{CM}$ group, that increase contracted significantly in the CM+GSPE group. Based on these results, we concluded that GSPE provided a renoprotective effect by reducing oxidative damage and apoptosis.

There are a number of limitations to this evaluation of the efficacy of GSPE in preventing CIN nephropathy.
First is the fact that this is an experimental study and there are no studies evaluating the efficacy in preventing CIN in humans. However, clinical studies have shown that GSPE ameliorates symptoms in patients with chronic pancreatitis [31], and another clinical study showed that it has a positive impact on lipid profile in hyperlipidemic patients [32]. Another limitation is that GSPE was started approximately 1 week before exposure to CM. This situation also appears in studies evaluating the efficacy of GSPE in preventing other experimental organ toxicities. On the basis of the few clinical studies available, we think that it can also be effective in preventing CIN when given simultaneously with CM exposure. However, this needs to be supported, primarily by experimental studies. Clinical studies supporting our work on this subject are needed.

In conclusion, this study is the first in the literature to demonstrate that GSPE prevents CIN development by reducing BUN, creatinine levels and renal histopathological alteration. Moreover, we showed that GSPE exhibits this effect by reducing oxidative injury and apoptosis. Further comprehensive and detailed experimental and clinical studies are needed to investigate the preventive effect of GSPE in CIN.

\section{Acknowledgements}

This study was supported by the Scientific Research Fund of Karadeniz Technical University. The authors would like to thank Kale Natural Herbal Products Food Cosmetics and Agriculture Ltd for providing the grape seed extract used in this study.

\section{Disclosure Statement}

The authors have no conflicts of interest to disclose.

References

$$
\begin{aligned}
& \text { Morcos SK, Thomsen HS, Webb JA: Con- } \\
& \text { trast-media-induced nephrotoxicity: a con- } \\
& \text { sensus report. Contrast Media Safety Com- } \\
& \text { mittee, European Society of Urogenital } \\
& \text { Radiology (ESUR). Eur Radiol 1999;9: } \\
& \text { 1602-1613. } \\
& \text { Itoh Y, Yano T, Sendo T, Oishi R: Clinical and } \\
& \text { experimental evidence for prevention of } \\
& \text { acute renal failure induced by radiographic } \\
& \text { contrast media. J Pharmacol Sci 2005;97: } \\
& \text { 473-488. } \\
& \text { Heyman SN, Rosen S, Khamaisi M, Idée JM, } \\
& \text { Rosenberger C: Reactive oxygen species and } \\
& \text { the pathogenesis of radiocontrast-induced } \\
& \text { nephropathy. Invest Radiol 2010;45:188- } \\
& \text { 195. }
\end{aligned}
$$


-4 Bagchi D, Bagchi M, Stohs S, Ray SD, Sen CK, Preuss HG: Cellular protection with proanthocyanidins derived from grape seeds. Ann NY Acad Sci 2002;957:260-270.

$\checkmark 5$ Bagchi D, Sen CK, Ray SD, Das DK, Bagchi M, Preuss HG, Vinson JA: Molecular mechanisms of cardioprotection by a novel grape seed proanthocyanidin extract. Mutat Res 2003;523:87-97.

-6 Bagchi D, Garg A, Krohn RL, Bagchi M, Tran MX, Stohs SJ: Oxygen free radical scavenging abilities of vitamins $\mathrm{C}$ and $\mathrm{E}$, and a grape seed proanthocyanidin extract in vitro. Res Commun Mol Pathol Pharmacol 1997;95: 179-189.

7 Colbay M, Yuksel S, Uslan I, Acarturk G, Karaman O, Bas O, Mollaoglu H, Yagmurca M, Ozen OA: Novel approach for the prevention of contrast nephropathy. Exp Toxicol Pathol 2010;62:81-89.

8 Uchiyama M, Mihara M: Determination of malonaldehyde precursor in tissues by thiobarbituric acid test. Analyt Biochem 1978; 86:271-278.

-9 Harma M, Harma M, Erel O: Increased oxidative stress in patients with hydatidiform mole. Swiss Med Wkly 2003;133:563-566.

10 Heyman SN, Rosenberger C, Rosen S: Regional alterations in renal haemodynamics and oxygenation: a role in contrast mediuminduced nephropathy. Nephrol Dial Transplant 2005;20:6-11.

-11 Sochman J, Peregrin JH, Bürgelová M, Kopkan L, Kramer HJ, Cervenka L: N-acetylcysteine attenuates iodine contrast agent-induced nephropathy in 5/6-nephrectomized rats. Kidney Blood Press Res 2010;33:149156.

-12 Spargias K, Alexopoulos E, Kyrzopoulos S, Iokovis P, Greenwood DC, Manginas A, Voudris V, Pavlides G, Buller CE, Kremastinos D, Cokkinos DV: Ascorbic acid prevents contrast-mediated nephropathy in patients with renal dysfunction undergoing coronary angiography or intervention. Circulation 2004;110:2837-2842.

13 Mueller C: Prevention of contrast-induced nephropathy with volume supplementation. Kidney Int 2006;100:16-19.
4 Rudnick MR, Goldfarb S, Wexler L, Ludbrook PA, Murphy MJ, Halpern EF, Hill JA, Winniford M, Cohen MB, VanFossen DB: Nephrotoxicity of ionic and nonionic contrast media in 1,196 patients: a randomized trial. The Iohexol Cooperative Study. Kidney Int 1995;47:254-261.

15 Romano G, Briguori C, Quintavalle C, Zanca C, Rivera NV, Colombo A, Condorelli G: Contrast agents and renal cell apoptosis. Eur Heart J 2008;29:2569-2576.

16 Briguori C, Quintavalle C, De Micco F, Condorelli G: Nephrotoxicity of contrast media and protective effects of acetylcysteine. Arch Toxicol 2011;85:165-173.

17 Finn WF: The clinical and renal consequences of contrast-induced nephropathy. Nephrol Dial Transplant 2006;21:2-10.

18 Merten GJ, Burgess WP, Gray LV, Holleman JH, Roush TS, Kowalchuk GJ, Bersin RM, Van Moore A, Simonton CA 3rd, Rittase RA, Norton HJ, Kennedy TP: Prevention of contrast-induced nephropathy with sodium bicarbonate: a randomized controlled trial. JAMA 2004;291:2328-2334

19 Wróbel W, Sinkiewicz W, Gordon M, Woźniak-Wiśniewska A: Oral versus intravenous hydration and renal function in diabetic patients undergoing percutaneous coronary interventions. Kardiol Pol 2010;68: 1015-1012.

20 Birck R, Krzossok S, Markowetz F, Schnülle P, van der Woude FJ, Braun C: Acetylcysteine for prevention of contrast nephropathy: meta-analysis. Lancet 2003;362:598-603.

21 Briguori C, Colombo A, Violante A, Balestrieri P, Manganelli F, Paolo Elia P, Golia B, Lepore S, Riviezzo G, Scarpato P, Focaccio A, Librera M, Bonizzoni E, Ricciardelli B: Standard vs. double dose of $\mathrm{N}$-acetylcysteine to prevent contrast agent associated nephrotoxicity. Eur Heart J 2004;25:206-211.

22 ACT Investigators: Acetylcysteine for prevention of renal outcomes in patients undergoing coronary and peripheral vascular angiography: main results from the randomized Acetylcysteine for Contrast-induced nephropathy Trial (ACT) Circulation 2011; 124:1250-1259.

23 Ray SD, Patel D, Wong V, Bagchi D: In vivo protection of DNA damage-associated apoptotic and necrotic cell deaths during acetaminophen-induced nephrotoxicity, amiodarone-induced lung toxicity and doxorubicin-induced cardiotoxicity by a novel IH636 grape seed proanthocyanidin extract. Res Commun Mol Pathol Pharmacol 2000;107: 137-166.
4 Yousef MI, Saad AA, El-Shennawy LK: Protective effect of grape seed proanthocyanidin extract against oxidative stress induced by cisplatin in rats. Food Chem Toxicol 2009; 47:1176-1183.

25 Saad AA, Youssef MI, El-Shennawy LK: Cisplatin-induced damage in kidney genomic DNA and nephrotoxicity in male rats: the protective effect of grape seed proanthocyanidin extract. Food Chem Toxicol 2009;47: 1499-1506.

26 Yanarates O, Guven A, Sizlan A, Uysal B, Akgul O, Atim A, Ozcan A, Korkmaz A, Kurt E: Ameliorative effects of proanthocyanidin on renal ischemia/reperfusion injury. Ren Fail 2008;30:931-938.

27 Safa J, Argani H, Bastani B, Nezami N, Rahimi Ardebili B, Ghorbanihaghjo A, Kalagheichi H, Amirfirouzi A, Mesgari M, Soleimany Rad J: Protective effect of grape seed extract on gentamicin-induced acute kidney injury. Iran J Kidney Dis 2010;4:285-291.

28 Ray SD, Kumar MA, Bagchi D: A novel proanthocyanidin IH636 grape seed extract increases in vivo Bcl-XL expression and prevents acetaminophen-induced programmed and unprogrammed cell death in mouse liver. Arch Biochem Biophys 1999;369:42-58.

29 Sato M, Bagchi D, Tosaki A, Das DK: Grape seed proanthocyanidin reduces cardiomyocyte apoptosis by inhibiting ischemia/reperfusion-induced activation of JNK-1 and CJUN. Free Radic Biol Med 2001;31:729-737.

- 30 Efrati S, Berman S, Ilgiyeav I, Siman-Tov Y, Averbukh Z, Weissgarten J: Differential effects of $\mathrm{N}$-acetylcysteine, theophylline or bicarbonate on contrast-induced rat renal vasoconstriction. Am J Nephrol 2009;29:181191.

31 Banerjee B, Bagchi D: Beneficial effects of a novel IH636 grape seed proanthocyanidin extract in the treatment of chronic pancreatitis. Digestion 2001;63:203-206.

32 Preuss HG, Wallerstedt D, Talpur N, Tutuncuoglu SO, Echard B, Myers A, Bui M, Bagchi D: Effects of niacin-bound chromium and grape seed proanthocyanidin extract on the lipid profile of hypercholesterolemic subjects: a pilot study. J Med 2000;31:227-246. 